\title{
Peningkatan Hasil Belajar Membaca Permulaan dengan Model Permainan Bahasa pada Siswa Kelas 1 SDN 3 Tempuharjo Tahun Ajaran 2018/2019
}

\section{Sutarno}

SDN 3 Tempurharjo

sutarnospd525@gmail.com

\author{
Article History \\ accepted 01/02/2020
}

approved 01/03/2020

published 01/04/2020

\begin{abstract}
The process of learning to read the beginning of class I semester 1 SD Negeri 3 Tempurharjo year 2018/2019 lessons are still far from expectation. The less precise use of learning models impacts The students ' low interest and attention in following the learning process. The low interest in student learning affects the low learning outcomes that students obtain. The average of KI-3 learning results obtained by 58.4 students with the classical learning, 53.84\%, and the average Ki-4 learning results are obtained 57.7 students with a Classical Study of 53.84\%. The problem Solving effort was implemented in 2 cyclesusing the learning languagegame model. The results of the study showed that the language game learning model could improve the learning process to read The beginning of class I semester 1 SDN 3 Tempurharjo in lesson 2018/2019 from enough Good to be good. Through language Games can also improve The results of learning to read The beginning of students grade I semester 1 SDN 3 Tempurharjo years lesson 2018/2019 with an increase in the average learning outcomes of 13.1. Learning Outcomes solve problems related to reading The beginning also increased after The study of language games on students of class I Semester 1 SDN 3 Tempurharjo Year lesson 2018/2019 with The average increase of learning Outcomes was 15.4.
\end{abstract}

Keywords: Read the Beginning, Language Games, SDN 3 Tempurharjo

\begin{abstract}
Abstrak
Proses pembelajaran membaca permulaan pada kelas I semester 1 SD Negeri 3 Tempurharjo tahun pelajaran 2018/2019 masih jauh dari harapan. Penggunaan model pembelajaran yang kurang tepat berdampak pada rendahnya minat dan perhatian siswa dalam mengikuti proses pembelajaran.Rendahnya minat belajar siswa berdampak pada rendahnya hasil belajar yang diperoleh siswa. Rata-rata hasil belajar KI-3 yang diperoleh siswa 58,4 dengan ketuntasan belajar klasikal 53,84 \% sedangkan rata-rata hasil belajar $\mathrm{KI}-4$ yang diperoleh siswa 57,7 dengan ketuntasan belajar klasikal 53,84\%. Usaha pemecahan masalah dilaksanakan dalam 2 siklus dengan menggunakan model pembelajaran Permainan Bahasa. Hasil penelitian menunjukkan model pembelajaran Permainan Bahasa dapat meningkatkan proses pembelajaran membaca permulaan pada kelas awal kelas I semester 1 SDN 3 Tempurharjo tahun pelajaran 2018/2019 dari cukup baik menjadi baik. Melalui Permainan Bahasa juga dapat meningkatkan hasil belajar membaca permulaan pada siswa kelas I semester 1 SDN 3 Tempurharjo tahun pelajaran 2018/2019 dengan peningkatan rata-rata hasil belajar sebesar 13,1. Hasil belajar menyelesaikan masalah yang berkaitan dengan membaca permulaan juga meningkat setelah diberikan pembelajaran Permainan Bahasa pada siswa kelas I semester 1 SDN 2 Tempurharjo tahun pelajaran 2018/2019 dengan peningkatan rata-rata hasil belajar sebesar 15,4.
\end{abstract}

Kata kunci: Membaca Permulaan, Model Permainan Bahasa, SDN 2 Tempurharjo 


\section{PENDAHULUAN}

Membaca merupakan salah satu ketrampilan berbahasa yang diajarkan dalam mata pelajaran bahasa Indonesia di sekolah dasar. Membaca permulaan merupakan tahapan proses belajar membaca bagi murid sekolah dasar kelas awal (Kelas I dan Kelas II).Secara teoretik proses membaca permulaan dilakukan melalui tiga tahapan. Tahap pertama disebut Visual Memory (VM). Pada tahap ini huruf, suku kata, kata, dan kalimat terlihat sebagai lambang grafis. Tahap kedua disebut Phonological Memory (PM). Pada tahap ini terjadi proses pembunyian lambang grafis yang sudah terekam pada tahap VM. Tahap ketiga disebut Semantic Memory (SM). Pada tahap ini terjadi proses pemahaman terhadap kata dan kalimat.

Aspek tersebut dibagi menjadi dua kelompok besar, yaitu (1) ketrampilan yang bersifat menerima (reseptif) yang meliputi ketrampilan membaca dan menyimak, (2) ketrampilan yang bersifat mengungkap (produktif) yang meliputi ketrampilan menulis dan berbicara (Muchlisoh, 1992: 119). Pembelajaran Bahasa Indonesia di Sekolah Dasar (SD) bertujuan meningkatkan kemampuan siswa berkomunikasi secara efektif, baik lisan maupun tertulis. Ketrampilan membaca sebagai salah satu ketrampilan berbahasa tulis yang bersifat reseptif perlu dimiliki siswa SD agar mampu berkomunikasi secara tertulis. oLeh karena itu, peranan pengajaran Bahasa Indonesia khususnya pengajaran membaca di SD menjadi sangat penting. Peran tersebut semakin penting bila dikaitkan dengan tuntutan

pemilikan kemahir wacanaan dalam abad informasi (Joni, 1990). Pengajaran Bahasa Indonesia di SD yang bertumpu pada kemampuan dasar membaca dan menulis juga perlu diarah kan pada tercapainya kemahir wacanaan.

Ketrampilan membaca dan menulis, khususnya ketrampilan membaca harus segera dikuasai oleh para siswa di SD karena ketrampilan ini secara langsung berkaitan dengan seluruh proses belajar siswa di SD. Keberhasilan belajar siswa dalam mengikuti proses kegiatan belajar-mengajar di sekolah Sangat ditentukan oleh penguasaan kemampuan membaca mereka. Siswa yang tidak mampu membaca dengan baik akan mengalami kesulitan dalam mengikuti kegiatan pembelajaran untuk semua mata pelajaran. Siswa akan mengalami kesulitan dalam menangkap dan memahami informasi yang disajikan dalam berbagai buku pelajaran, buku-buku bahan penunjang dan sumber-sumber belajar tertulis yang lain. Akibatnya, kemajuan belajarnya juga lamban jika dibandingkan dengan teman-temannya yang tidak mengalami kesulitan dalam membaca. Menurut pandangan "whole language" membaca tidak diajarkan sebagai suatu pokok bahasan yang berdiri sendiri, melainkan merupakan satu kesatuan dalam pembelajaran bahasa bersama dengan ketrampilan berbahasa yang lain. Kenyataan tersebut dapat dilihat bahwa dalam proses pembelajaran bahasa, ketrampilan berbahasa tertentu dapat dikaitkan dengan ketrampilan berbahasa yang lain. Pengaitan ketrampilan berbahasa yang dimaksud tidak selalu melibatkan keempat ketrampilan berbahsa sekaligus, melainkan dapat hanya mengakut dua ketrampilan saja sepanjang aktivitas berbahasa yang dilakukan bermakna. Pembelajaran membaca di SD dilaksanakan sesuai dengan pembedaan ataskelas-kelasawal dan kelas-kelas tinggi. Pelajaran membaca dan menulis di kelaskelas awal disebut pelajaran membaca dan menulis permulaan, sedangkan di kelas-kelas tinggi disebut pelajaran membaca dan menulis lanjut. Pelaksanaan membaca permulaan di kelas I sekolah dasar dilakukan dalam dua tahap, yaitu membaca periode tanpa buku dan membaca dengan menggunakan buku. Pembelajaran membaca tanpa buku dilakukan dengan cara mengajar dengan menggunakan media atau alat peraga selain buku misalnya kartu gambar, kartu huruf, kartu kata dan kartu kalimat, sedangkan membaca dengan buku merupakan kegiatan membaca dengan menggunakan buku sebagai bahan pelajaran.Tujuan membaca permulaan di kelas I adalah agar "Siswa dapat membaca kata-kata dan kalimat sederhana dengan lancar dan tepat (Depdikbud, 1994/1995: 122) 
Dengan kata lain, guru memegang peranan yang strategis dalam meningkatkan ketrampilan membaca siswa. Peranan strategis tersebut menyangkut peran guru sebagai fasilitator, motivator, sumber belajar, dan organisator dalam proses pembelajaran.Guru yangberkompetensi tinggi akan sanggup menyelenggarakan tugas untuk mencerdaskan bangsa, mengembangkan pribadi manusia Indonesia seutuhnya dan membentuk ilmuwan dan tenaga ahli. Menurut Badudu (1993: 131) pelaksanaan pembelajaran Bahasa Indonesia di SD - SMU ialah guru terlalu banyak menyuapi, tetapi kurang menyuruh siswa aktif membaca, menyimak, menulis dan berbicara. Proses belajar-mengajar di kelas tidak relevan dengan yang diharapkan, akibatnya kemampuan membaca siswa rendah. Untuk mengoptimalkan pembelajaran membaca permulaan di SD salah satu alternatif yang dapat dilakukan ialah melalui permainan bahasa. Guru perlu menyediakan bahan yang menarik yang dapat menyajikan tantangan bagi siswa untuk giat secara aktif dan kreatif "mengotak-atik" apa yang dihadapinya. Bahan tersebut hasrulah sesuai dengan perkembangan emosi dan sosial anak. Anak di kelas permulaan (usia 6 - 8 tahun) berada pada fase bermain. Dengan bermain anak akan senang belajar, semakin senang anak semakin banyak yang diperolehnya. Permainan memiliki peranan penting dalam perkembangan kognitif dan sosial anak (Dworetzky, 1990). Karena dalam bermain guru mendukung anak belajar dan mengembangkannya (Wood, 1996).

\section{METODE}

Penelitian ini merupakan pengalaman mengajar penulis di sebuah Sekolah Dasar. Pada tahun pelajaran 2018/2019, dengan sampel responden yang berjumlah 7 , yang terdiri dari laki-laki 6 orang dan perempuan 1 orang. Hal yang ingin dicapai pada pembelajaran permainan bahasa adalah keaktifan belajar siswa dan hasil belajar

Pendekatan penelitian yang digunakan adalah mixed method. Metodologi ini dianggap tepat karena digunakan untuk mengetahui tepat atau tidaknya desain pembelajaran yang telah diterapkan. Yaitu untuk mengetahui apakah ada peningkatan keaktifan belajar dan prestasi belajar.

Pendekatan pembelajaran yang diterapkan dalam penelitian ini merupakan pendekatan pembelajaran yang diciptakan oleh penulis untuk memecahkan masalah yang dihadapi penulis dalam pembelajaran yang tepat, sehingga dibutuhkan mixed method dalam penelitian ini, dengan memadukan metode kualitatif dan kuantitatif.

Metode ini dapat direplikasi oleh peneliti yang lain yang melakukan penelitian di bidang yang sama, karena telah mengikuti kaidah-kaidah ilmiah.

\section{HASIL DAN PEMBAHASAN}

Pembelajaran membaca permulaan di kelas I SD Negeri 3 Tempurharjo tahun 2018/2019 dilaksanakan dengan menggunakan metode yang bervariasi, media yang dianggap dapat menarik perhatian siswa serta menggunakan model pembelajaran kontekstual yang mengaitkan materi dengan situasi dunia nyata di sekitar siswa. Penggunaan model pembelajaran yang kurang tepat berdampak pada rendahnya minat dan perhatian siswa dalam mengikuti pembelajaran. Salah satu indikator rendahnya minat siswa dalam belajar membaca permulaan dapat dilihat saat proses pembelajaran yaitu anak enggan merespon pertanyaan guru dan tidak mau bertanya jika mengalami kesulitan. Beberapa diantara mereka bahkan asyik bermain sendiri dan tidak memperhatikan penjelasan guru. Berdasarkan hasil pengamatan diperoleh data dari 3 (tiga) indikator proses pembelajaran sebagai berikut :

a. Keaktifan siswa menjawab pertanyaan

Berdasarkan hasil pengamatan proses pembelajaran membaca permulaan di

kelas I, sebagian besar siswa lebih memilih diam ketika diberi pertanyaan. Guru sudah memberikan stimulasi dengan berbagai cara agar siswa mau dan berani 
menjawab pertanyaan. Hasil pengamatan menunjukkan dari 7 siswa terdapat 2 siswa yang aktif menjawab pertanyaan. Data tersebut tersaji dalam tabel berikut :

Tabel 7

Data Prasiklus Keaktifan siswa menjawab pertanyaan

\begin{tabular}{|l|c|c|}
\hline \multicolumn{1}{|c|}{ Indikator } & Ya & Tidak \\
\hline Keaktifan siswa menjawab pertanyaan & 2 & 5 \\
\hline Prosentase & $28,57 \%$ & $71,42 \%$ \\
\hline
\end{tabular}

b. Antusias siswa dalam proses pembelajaran

Berdasarkan hasil pengamatan proses pembelajaran membaca permulaan di kelas I menunjukkan antusias siswa dalam proses pembelajaran masih kurang. Hal ini terlihat saat proses pembelajaran berlangsung beberapa anak asyik dengan dunianya sendiri. Ada yang memain-mainkan alat tulisnya, ada yang bergurau dengan temannya, ada pula yang meletakkan kepalanya di atas meja seakan tak peduli dengan pembelajaran yang disampaikan guru. Hasil pengamatan menunjukkan dari 7 siswa terdapat 4 siswa yang antusias dalam proses pembelajaran. Data tersebut tersaji dalam tabel berikut :

Tabel 8

Data Prasiklus Antusias siswa dalam proses pembelajaran

\begin{tabular}{|l|c|c|}
\hline \multicolumn{1}{|c|}{ Indikator } & Ya & Tidak \\
\hline Antusias siswa dalam proses & 4 & 3 \\
\hline Prosentase & $57,14 \%$ & $42,85 \%$ \\
\hline
\end{tabular}

c. Kerja sama siswa dalam kelompok

Berdasarkan hasil pengamatan proses pembelajaran membaca permulaan di kelas I menunjukkan kerja sama siswa saat diskusi kelompok juga masih rendah. Sebagian siswa lebih memanfaatkan waktu diskusi untuk bermain dan bergurau. Pekerjaan kelompok lebih dibebankan kepada ketua kelompok atau anggota yang lebih pandai sehingga diskusi kelompok tidak berjalan maksimal. Hasil pengamatan menunjukkan dari 7 siswa terdapat 4 siswa yang bekerja sama dalam kelompok. Data tersebut tersaji dalam tabel berikut :

Tabel 9

Data Prasiklus Kerja sama siswa dalam kelompok

\begin{tabular}{|l|c|c|}
\hline \multicolumn{1}{|c|}{ Indikator } & Ya & Tidak \\
\hline Kerja sama siswa dalam kelompok & 4 & 3 \\
\hline Prosentase & $57,14 \%$ & $42,86 \%$ \\
\hline
\end{tabular}

Rekapitulasi data proses pembelajaran berdasarkan ketiga indikator tersebut tersaji dalam tabel berikut : 
Tabel 10

Data Prasiklus Rekapitulasi data proses pembelajaran

\begin{tabular}{|l|l|c|r|}
\hline No. & Indikator & Jumlah & Prosentase \\
\hline 1. & Keaktifan siswa menjawab pertanyaan & 2 & $28,77 \%$ \\
\hline 2. & Antusias siswa dalam proses pembelajaran & 4 & $57,14 \%$ \\
\hline 3. & Kerja sama siswa dalam kelompok & 4 & $57,14 \%$ \\
\hline \multicolumn{2}{|c|}{ Rata-rata } & $47,68 \%$ \\
\hline & Kategori & Cukup Baik \\
& & & \\
\hline
\end{tabular}

Berdasarkan tabel di atas dapat diketahui bahwa proses pembelajaran membaca permulaan yang telah dilaksanakan belum berjalan baik. Tingkat keaktifan siswa dalam menjawab pertanyaan hanya $28,77 \%$ yang termasuk dalam kategori kurang baik. Tingkat antusias siswa dalam proses pembelajaran hanya 57,16 \% dalam kategori cukup baik sedangkan kerja sama siswa dalam kelompok hanya 57,16 \% juga dalam kategori cukup baik. Rata-rata dari ketiga indikator proses pembelajaran hanya 47,68 $\%$ termasuk dalam kategori cukup baik.

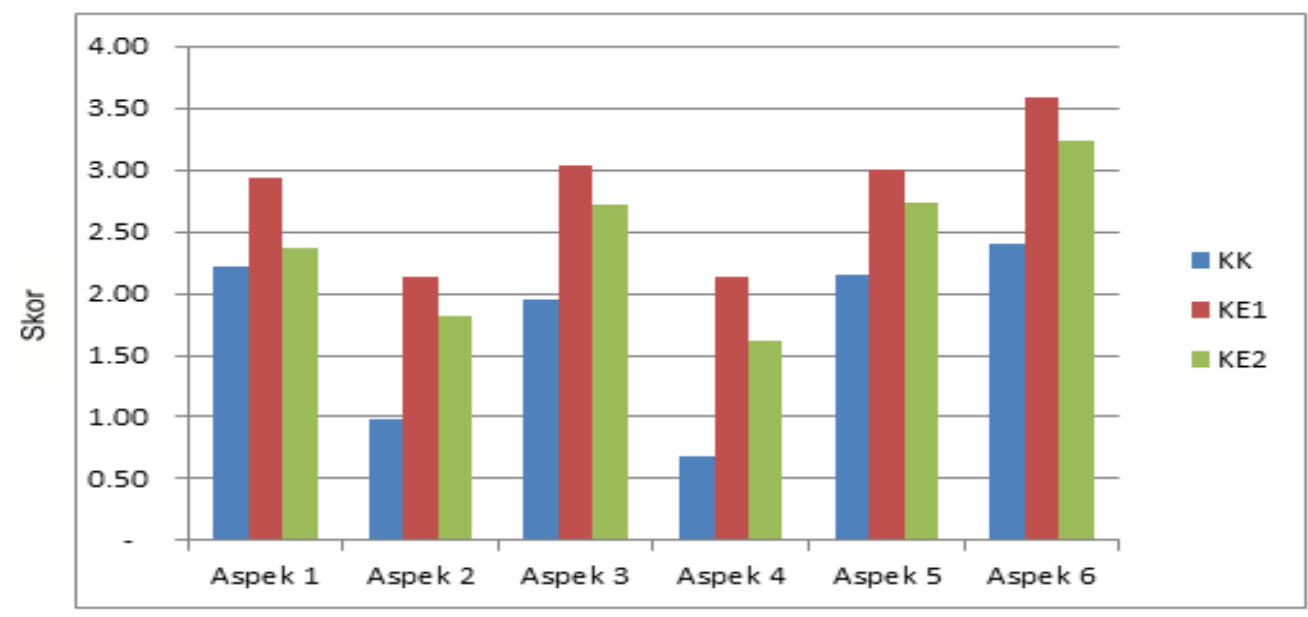

Keterampilan Proses Sains 


\section{SIMPULAN}

1. Proses pembelajaran dengan menggunakan model Permainan Bahasa untuk meningkatkan hasil belajar Membaca Permulaan pada siswa kelas I semester 1 SDN 3 Tempurharjo tahun pelajaran 2018/2019 berjalan sesuai dengan RPP yang disusun, lebih efektif dan meningkat dari CUKUP BAIK menjadi BAIK.

2. Terdapat peningkatan hasil belajar membaca permulaan setelah diberikan pembelajaran dengan model Permainan bahasa pada siswa kelas I semester 1 SDN 3 Tempurharjo tahun pelajaran 2018/2019 sebesar 13,1 dengan peningkatan ketuntasan belajar sebesar $23,08 \%$.

3. Terdapat peningkatan hasil belajar menyelesaikan masalah yang berkaitan dengan membaca permulaan setelah diberikan pembelajaran dengan model Permainan Bahasa pada siswa kelas I semester 1 SDN 3 Tempurharjo tahun pelajaran 2018/2019 sebesar 15,4 dengan peningkatan ketuntasan belajar sebesar $30,78 \%$.

\section{DAFTAR PUSTAKA \\ Aris,Shoimin.2014.68 Model Pembelajaran Inovatif dalam Kurikulum 2013,Yogyakarta:Ar-Ruzz Media.}

Darmiyati Zuchdi dan Budiasih, 2001. Pendidikan Bahasa dan Sastra Indonesia di Kelas Rendah. Yogyakarta: PAS.

Departemen Pendidikan Nasional. 2006. Kurikulum KTSP. Jakarta: Dirjen Manajemen Pendidikan Dasar dan Menengah.

Djago Tarigan, 1997. Pendidikan dan Bahasa Sastra Indonesia di Kelas Rendah. Jakarta: Universitas Terbuka.

Djauzak Ahmad, dkk. 1996. Metodik Khusus Pengajaran Bahasa Indonesia di Sekolah Dasar. Jakarta: Dirjen Pendidikan Dasar Departemen Pendidikan Nasional.

Dimyati dan Mujiono, 2002. Belajar dan Pembelajaran. Jakarta: Rineka Cipta.

Etin Solihatin. 2005. Pengaruh Kooperatif Learning terhadap Belajar IPS Ditinjau dari Gaya Belajar. Jakarta: Bumi Aksara.

Farida Rahim. 2008. Pengajaran Membaca di Sekolah Dasar. Jakarta: Bumi Aksara.

Matthew B. Miles dan A. Michael Huberman. 2007. Analisis Data Kualitatif. Jakarta : Universitas Indonesia.

Mulyono Abdurrahman, 2003. Pendidikan Bagi Anak Berkesulitan Belajar. Jakarta: Rineka Cipta.

Murbiana Dhieni, dkk.2006. Metode Pengembangan Bahasa. Jakarta Universitas Terbuka.

Nurhasanah dan Didik Tumianta. 2007. Kamus Besar Bergambar Bahasa Indonesia untuk SD dan SMP. Jakarta PT. Bina Sarana Pustaka.

Oemar Hamalik, 1999. Kurikulum dan Pembelajaran. Jakarta: Bumi Aksara. 
Rukayah. 2004. Membaca Menulis Permulaan dan Alternatif Membantu Siswa yang Berkesulitan. Surakarta: Universitas Sebelas Maret.

Sabarti Akhadiah, dkk. 1993. Bahasa Indonesia I. Jakarta: Direktorat Jenderal Pendidikan Tinggi Departemen Pendidikan Nasional.

Sarwiji Suwandi. 2008. Penelitian Tindakan Kelas dan Penulisan Karya IImiah. Surakarta : Panitia Sertifikasi Guru.

Soli Abimanyu. 2008. Strategi Pembelajaran. Jakarta: Direktorat Jenderal Pendidikan Tinggi Departemen Pendidikan Nasional.

Sugiyanto, 2008. Model-Model Pembelajaran Inovatif. Surakarta: Panitia Sertifikasi Guru Rayon 13. 